\title{
Simulation of laboratory assignments to support students' learning of introductory inorganic chemistry
}

\author{
Jens Josephsen* and Agnieszka Kosminska Kristensen ${ }^{\dagger}$ \\ Department of Life Sciences and Chemistry, Roskilde University, Denmark \\ e-mail:phjens@ruc.dk
}

Received 1 March 2006, accepted 20 July 2006

\begin{abstract}
The goal of this investigation was to elucidate undergraduate chemistry students' response to the SimuLab computer-based learning environment, which simulates a 20 hours laboratory assignment. The SimuLab is a cognitive tool designed to help students to acquire experimental and analytical skills on the basis of a classical qualitative and quantitative analysis scheme and to develop their ability to interpret experimental results. Consistent with the intentions behind the design, students seemed to acknowledge the learning potential of the simulation program. They found it motivating and creating attention towards the practical application of declarative knowledge. We also found SimuLab to support students in the accomplishment of cognitive tasks and to enhance their skills in the context of the investigation. [Chem. Educ. Res. Pract., 2006, 7 (4), 266-279]
\end{abstract}

Keywords: computer-based learning environment, simulated laboratory environment, identification of inorganic compounds, cognitive tool, peer support, group work

\section{Introduction}

University chemistry teaching invariably includes laboratory exercises, investigations and experiments. The learning of empirical facts, chemical procedures and methods in chemistry depends heavily on the experience, which may be obtained from such teaching activities (Josephsen, 2003, and references therein). However, experimental work in teaching is both expensive and time consuming, and should therefore make the most effectively use of the allotted student time, staff time, and of the investment in the laboratory and its equipment, chemicals and other materials. Laboratory assignments require written as well as oral instruction. If the instructions are too ambitious with respect to what the students can manage to do and comprehend they are overloaded with information (Johnstone, 1997, 1999), and this may result in students simply following a recipe as a result of their cognitive limitations. This casts doubt on the effectiveness of such procedures and doesn't measure up to the efforts and other resources put into the activity. Due to limited time in the laboratory, students too often struggle with procedural issues, such as unfamiliar laboratory techniques and measurements related to the investigation, while they are expected to interpret the obtained data. Performing procedures is a lower order cognitive skill, but perturbations associated with accomplishment of this activity may interfere and diminish students reasoning (Johnstone, 1997).

In introductory university courses the purpose is not to get students to become professional on the manipulative side of the procedure. Rather, it is to introduce them to and give them first experience with chemicals, techniques and equipment. In such cases a laboratory simulation may function as a low-cost and fast extension of student lab time. Virtual investigations seem to be a promising kind of tool (Lajoie, 1993; Garratt, 1997) for

\footnotetext{
${ }^{\dagger}$ Present address: SUHR'S University College of Nutrition and Health, Copenhagen.
} 
several reasons and this has lead to the development of self-instructing, interactive computer based learning resources closely related to an actual course in introductory inorganic chemistry (Josephsen and Kristensen, 2002). The process of developing a cognitive tool like SimuLab is rather time consuming. However, since the first learning experience with it was positive, it was considered worthwhile to put effort into its further improvement and the ongoing investigation of students learning outcomes.

\section{The reduction of cognitive load}

Time has run out for rote learning of facts as the only university teaching strategy. As Langmuir (1950) stated it "Our schools and universities devote so much effort in imparting information to students that they almost neglect the far more important function of teaching the student how to get for himself what knowledge of any subject he may need". Still most of us draw upon a lot of empirical facts collected via this type of teaching, and it is beyond any doubt that such knowledge is useful and even necessary. However, one crucial point is that the amount of such knowledge has increased tremendously. Thus we may tend to overload our teaching with facts and declarative knowledge. But this is not only a problem because of changed teaching and learning styles. According to cognitive theories, human cognitive capacity is restricted (Miller, 1956, Simon, 1974) because of the limitations of our working memory (Baddeley, 1992). We can only pay attention to a certain amount of information and perform a limited number of task at any one time. If the amount of information to focus on, or task to perform exceeds our capacity it results in cognitive overload (Sweller, 1988; Sweller and Chandler, 1991). However, by decreasing this burden, more capacity is left over to accomplish the main task. Within the language of Cognitive Load Theory, which is a well established and developed point of view (Bannert, 2002), the way instructions are designed can reduce the extraneous cognitive load (ECL) and minimise the chances of overload.

According to automatic processing theory, lower level cognitive processes have to become automated before the learner has the necessary recourses available for higher order cognitive skills (Shiffrin and Schneider, 1977). Computer-based learning environments can evade the time-consuming automation process by performing lower level tasks for the learner, or simply by reducing the ECL of complex or demanding tasks (van Bruggen et al. 2002). It has been reported that the use of carefully designed computer-based learning environments in learning situations share cognitive load and result in enhancement of students' learning (Lajoi, 1993; Lajoi et al., 1998; Lajoi et al.,2001).

\section{Method}

\section{The course design}

Classical qualitative and quantitative analysis of relatively simple soluble salts or coordination compounds containing only simple inorganic ligands has for a long time been part of introductory inorganic chemistry. It still is, in spite of the fact that professional chemical analysis is currently far more advanced than chemical separation and identification reactions in test tubes and volumetric analysis. The reason for continuing to use such an 'anachronistic' element in teaching is simply that this type of simple and classical procedures has a great learning potential; it offers a practical setting which can give a lot of experience with chemical reactions. These simple procedures involve the handling of typical standard reagents such as acids and bases, oxidising and reducing agents, etc., using simple laboratory glassware, and they facilitate students' construction of knowledge about the field in a real context. In the theoretical part of such a course students are taught and acquire theoretical or declarative knowledge, i.e. knowledge about the physical and chemical properties of common inorganic compounds. In the laboratory part of the course students are supposed to put this 
declarative knowledge into practice by using it in the context of a realistic problem-solving task.

At Roskilde University, the introductory course in inorganic chemistry has a clear empirical orientation and is organised with around 40 hours in the lab and 40 hours in the class. It draws upon a general chemistry course, which deals with the basic principles and models of chemistry (i.e. stoichiometry, structure, bonding, chemical thermodynamics, equilibrium, kinetics etc.). The classical qualitative and quantitative analysis is the platform for the laboratory part of the inorganic chemistry course. It includes 20 hours of a laboratory investigation where simple soluble inorganic salts, in solution or in the solid state, containing common p-block anions [of $\mathrm{B}, \mathrm{C}, \mathrm{N}(+5,+3), \mathrm{P}, \mathrm{O}(-2,-1), \mathrm{S}(+6,+4,-2)$, halogens $(-1,+1,+3,+5$, +7 , not perchlorate)] and alkali metal cations and/or ammonium are identified and quantified. The second part of the laboratory assignments deals with the chemistry of hard and soft metal ions and the identification of them in a mixture or in a stoichiometric compound. The students accept this focus on the identification of 'unknowns' as a kind of play, realising that they are not expected to become professionally skilled in analysing inorganic chemicals. They certainly acknowledge the laboratory assignments as a means of getting experience with chemicals and techniques and see chemical principles and reactions in operation. Some even find it is fun.

The aim is first, to increase the students' experience and knowledge of chemical reactions and the physical and chemical properties of common inorganic compounds, and second, to increase the students' acquaintance with chemical principles (of classical quantitative, mostly volumetric, procedures and simple semi-micro techniques, used to follow simple reactions).

To pursue such aims, the experimental work should be co-ordinated with and supported by other activities. It is a common experience that a laboratory manual is a difficult learning tool for students: it hasn't got a text book format, it is overloaded with information, because it should be exhaustive and precise in the description of procedures, and it is organised according to its analytical purpose; it requires instruction or a 'reading manual' (which in itself should be self explanatory).

The use of pre and post labs has been one way of improving (learning and) teaching (Johnstone et al., 1994; Johnstone et al., 1998). A preparatory worksheet was given to the students a week before the laboratory experiment session. Working with this worksheet was a vehicle to enhance the students' pre-knowledge and to make them consider a number of important issues in relation to the experiment. It was shown that the students performed better in the post lab activities when they had completed this type of pre lab (Johnstone et al., 1994, Johnstone, 1997).

In the present course, the students also study the same type of identification problems by the paper and pencil method, and they practice the application of general principles and empirical facts in inorganic chemistry in this way. The final written test includes the identification of a mineral by some of the techniques and procedures they have met in the laboratory assignments and by classical or other quantitative methods which are described briefly in the test paper and which they haven't necessarily met before. During the course the students meet quite a number of such problems, so in a way the problems function as a kind of pre labs, and the two types of learning and teaching resources - the laboratory assignments and the written problems - support each other. An example of this is given in the Box below. 


\section{Box: Example of a written problem}

The last fraction of salts obtained from the evaporation of Dead Sea water is a very soluble, pure white compound $\mathbf{A}$.

1. Its aqueous solution is neutral, and when a drop of it is added to a saturated solution of sodium hexanitrocobaltate(III) in dilute acetic acid an orange-yellow precipitate appears.

2. The concentration in solution $\mathbf{B}$ (made by dissolving $584 \mathrm{mg} \mathbf{A}$ in $100 \mathrm{ml}$ of water) of the component of $\mathbf{A}$ identified in test 1 is determined by flame photometry to be $0.021 \mathrm{M}$.

3. The addition of silver nitrate to a solution of $\mathbf{A}$ in dilute nitric acid gives a white precipitate, which is soluble in $1 \mathrm{M}$ ammonium carbonate.

4. In a Mohr titration of $20.00 \mathrm{ml}$ of solution $\mathbf{B}, 12.56 \mathrm{ml}$ of $0.100 \mathrm{M}$ silver nitrate was used.

5. A white precipitate $\mathbf{C}$ is formed when a sodium carbonate solution is added to a portion of solution $\mathbf{B}$. C dissolves with effervescence in dilute acetic acid, and no precipitation is observed when ammonium oxalate is added. When solution $\mathbf{B}$ is treated with quinalizarine together with an excess of sodium hydroxide, a blue precipitate appears.

What is the empirical formula of $\mathbf{A}$ ?

Outline a volumetric method to determine quantitatively the component of $\mathbf{A}$ identified in solution $\mathbf{B}$ by the formation of the blue precipitate in test 5 , and give the number of $\mathrm{ml}$ of the $0.100 \mathrm{M}$ titrant to $20.00 \mathrm{ml}$ of solution $\mathbf{B}$.

A 'Virtual investigation' is another type of teaching and learning tool that seems to improve students learning. Recently we have developed and introduced this type of computerbased learning activity into the course. Thus, in addition to the laboratory assignment and the written problems, our students also have the third type of learning resource - the computer simulation of the laboratory assignment. An important feature, common to all three types of learning resources, is that facts and observations are given at the macroscopic level only. (What is done, as in 'Experimental', and what is observed, cf. 'Results'). The students' task is to transform the information that can be extracted from the experiments into chemical conclusions using chemical principles and empirical facts (cf. 'Discussion'). We started with a simulation of the first (20 hours) laboratory assignment of simple salts. Since our experience was rather positive, a similar simulation programme for the second part of the laboratory course was also developed (Josephsen, 2005). Similar simulation programmes have been reported (Woodfield et al., 2004) but without the quantitative dimension. In this paper we describe our experience with the implementation of the first part of the simulation - SimuLab - which has been in use for a couple of years now.

\section{Design of the computer programme}

SimuLab is an interactive, self-instructive computer simulation of the laboratory assignment. This virtual laboratory environment is an example of a cognitive tool (Lajoi 1993; Lajoi et al., 1998; Lajoi et al., 2001), i.e. a tool that can assist learners to accomplish cognitive tasks. In this case the task is to identify inorganic compounds using classical laboratory procedures and common laboratory reagents and equipment. The main rationale behind the design of this learning tool was to facilitate the learner's construction of knowledge by promoting students' ability to reason scientifically about classical analysis. SimuLab presents a task to the users and provides appropriate tools such as different laboratory procedures to enable them to solve the task. It also supports students with some degree of feedback and with help functions, such as tables of relevant chemical data, a 
numerical calculator and a facility to write down and store the users' own observations, comments, and conclusions.

Performing different tests and laboratory procedures requires only lower order cognitive skills. However, it is necessary for students to carry out these tests in order to collect data that enable them to predict and support (or reject) a hypothesis about the components of the investigated substances. By running simulations of the tests and laboratory procedures the SimuLab provides support for lower order cognitive skills and reduces students' cognitive load. The SimuLab can therefore promote the higher order skills required for scientific reasoning, such as choice of methods and the interpretation of data obtained through the investigation. In addition, the time consuming procedures are strongly accelerated in the SimuLab environment. Rather than spend time performing procedures, students can concentrate on interpretation of the results achieved through computer simulation. SimuLab provides opportunities for students to practise declarative knowledge acquired in the theoretical part of the course in the context of a realistic problem-solving task. At the same time the procedural challenges related to the carrying out of tests in the real laboratory are avoided.

In summary, the SimuLab is a type of learning tool that supports scientific inquiry and helps students to develop model-based reasoning. It aims to facilitate the generation of a hypothesis based on the analysis of an assigned (unknown inorganic) compound and the subsequent evaluation of results in order to assess this hypothesis. The SimuLab eliminates some important constraints by being provided on the web (Figure 1). It gives the students opportunities to 'perform' different laboratory procedures and investigate different substances outside the real laboratory at the time, speed, and place chosen by themselves.

\section{How SimuLab works}

The procedures in this electronic simulation follow the laboratory manual applied in the lab. SimuLab provides students' with an 'unknown' substance. As shown in the illustrated case the 'unknown' is a white solid, soluble in water (Figure 2). Students are expected to perform simulations of some introductory experiments as they would have done in the laboratory. There are several introductory experiments which could be chosen. To investigate the components of the 'unknown' students may choose from procedures provided in the introductory investigations (cf. menu on the left). For example, different ways of heating the 'unknown' can be chosen, one of which is to heat the solid in a flame.

After having observed the colour of the flame (Figure 3), we expect that students can interpret the result and note their assumption/ hypothesis (we hope they think of lithium in this case). The presence of lithium is subsequently confirmed by a specific chemical test. The programme provides feedback, which is automatically stored in a file, accessible in the menu under Results. The next step is to perform another test.

The redox properties (in the actual case, the result is shown in Figure. 4) and acid-base properties (cf. Figure 5) are some of the options, and both give important clues about distinctive features of the 'unknown'. Interpretation of these results may help to decide which components may and which may not be present in the 'unknown'. Further, the measurement of the $\mathrm{pH}$ of an aqueous solution of the 'unknown' (in this case the test leaves the universal indicator paper blue) shows, that we have sulphite. We expect the student to infer that these results strongly suggest that we have lithium sulfite. This assumption should finalise the qualitative part of the investigation. 
Figure 1: Appearance of the introduction to the programme SimuLab.
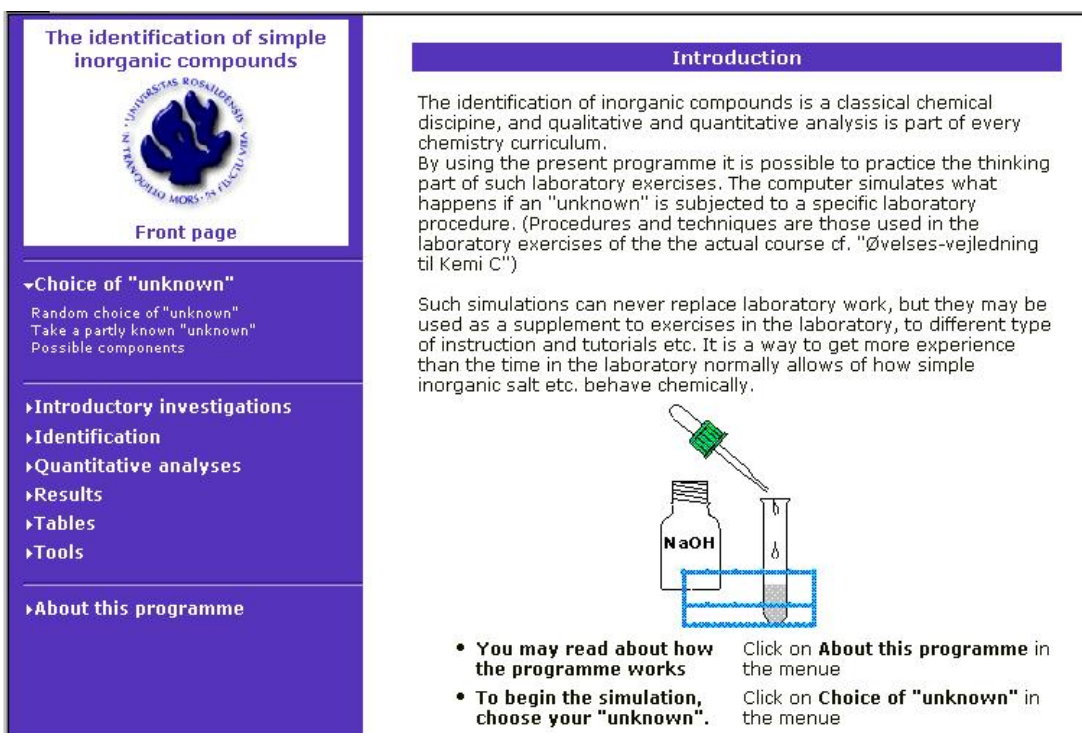

Figure 2: Choice of ‘unknown’ substance.
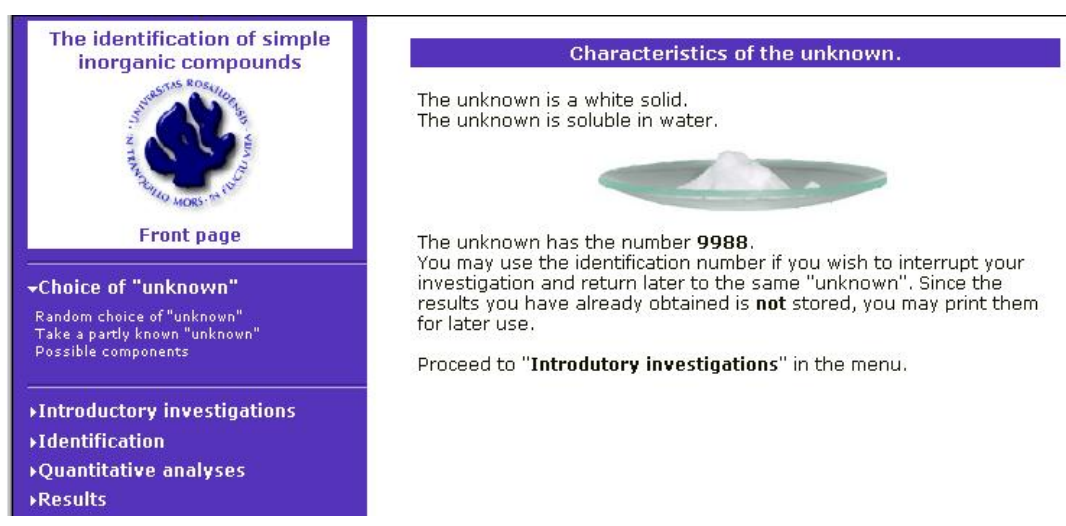

Figure 3: Heating of the 'unknown' in a flame.

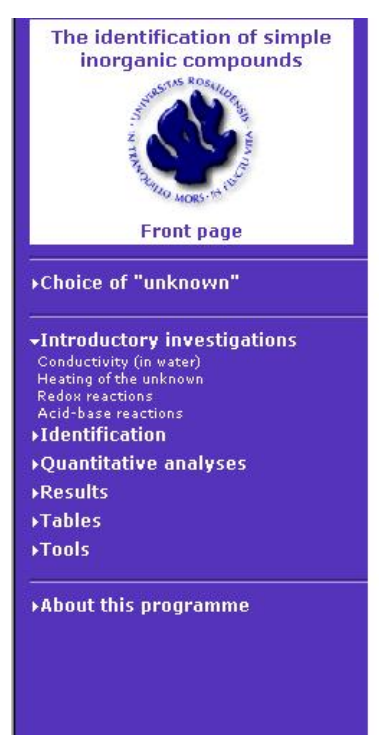

\section{Introductory investigations: Heating of the unknown}

A few grains are placed on a spatula. The spatula is heated in a flame is observed.

The result is seen on the figure:

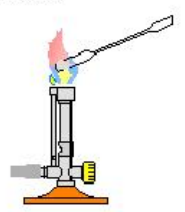

What does the colour of the flame tell about the unknown?

C The unknown contains lithium?

C The unknown contains sodium?

$C$ The unknown contains potassium?

$C$ It is not likely that the unknown contains any of the alkali metal Answer Reset 
Figure 4: The result of adding a drop of potassium permanganate to an aqueous solution of the 'unknown' indicates that it is reducing.
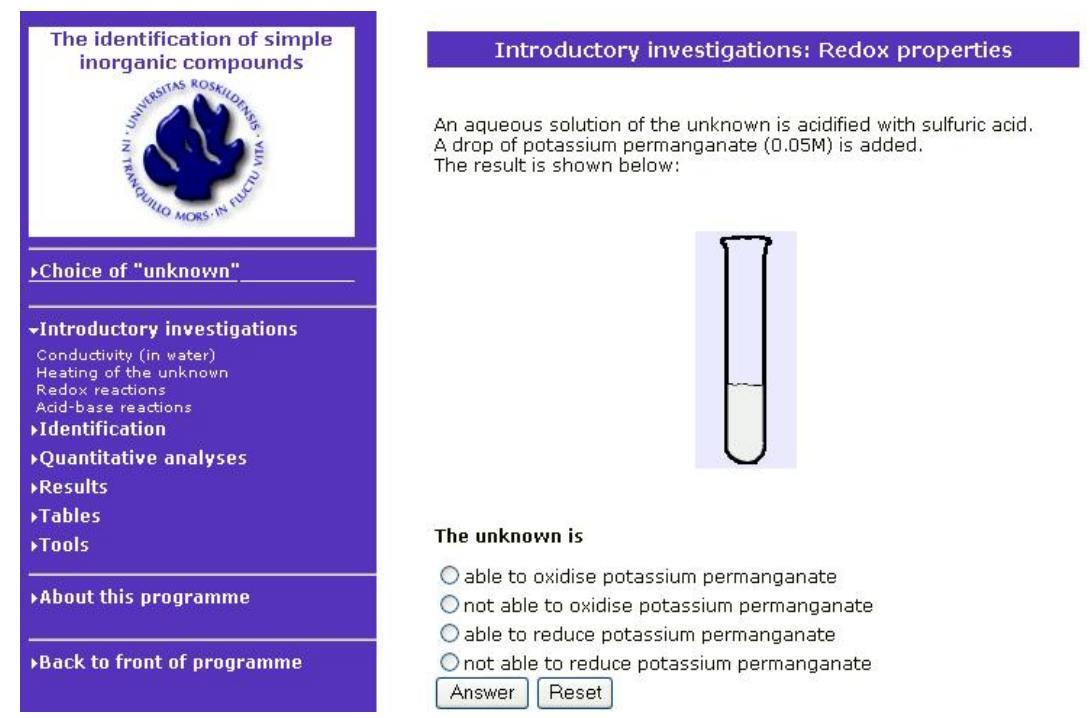

Figure 5: The result of looking for an acidic gas escaping from an acidic solution of the unknown indicates that it contains a corresponding base to either carbonic acid or sulfurous acid - and because of the result of the former experiment the component must be sulfite or hydrogen sulfite.

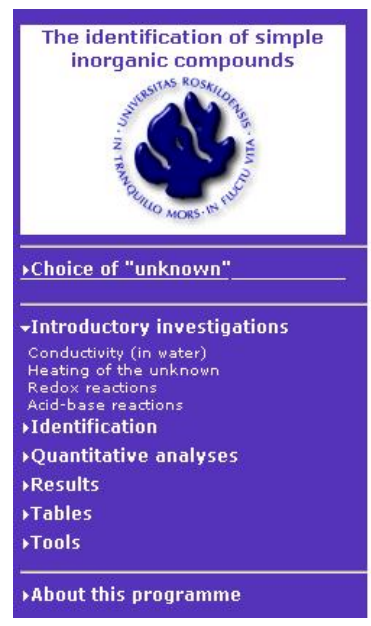

Introductory investigations: The addition of acid

To a test tube containing an aqueous solution of the unknown a little $2 \mathrm{M} \mathrm{HCl}$ is added

To another tube is added $5 \mathrm{dr}$. barium hydroxide water.

While heating in a water bath for 3 gast test tool. is gently pumped through the tool. It is observed if a white precipitate in the second test tube appears. The result is:

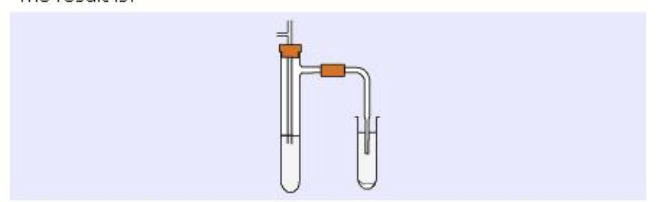

Does the addition of $2 \mathrm{M} \mathrm{HCl}$ result in the formation of an acidic gas?

No acid gas is formed An acid gas is formed Answer Reset

After having completed this first part of the investigation, the students are urged to make a quantification of both components. They are expected to use an acid-base, a redox titration, and a flame photometry measurement (illustrated in Figure 6), preceded by a calculation (which is checked by the computer) of how much of the 'unknown' should be weighed out in a given volume of water in order to get a required concentration, within the standard curve. The result of the flame photometry is illustrated in Figure. 6 and subsequently this result should be translated into the experimentally determined molar mass equivalent to one mole of lithium. This result and the result from the titration procedure(s) should then be combined, leading to a final conclusion about an empirical formula for the 'unknown'. 
Figure 6: Flame photometric determination of lithium.
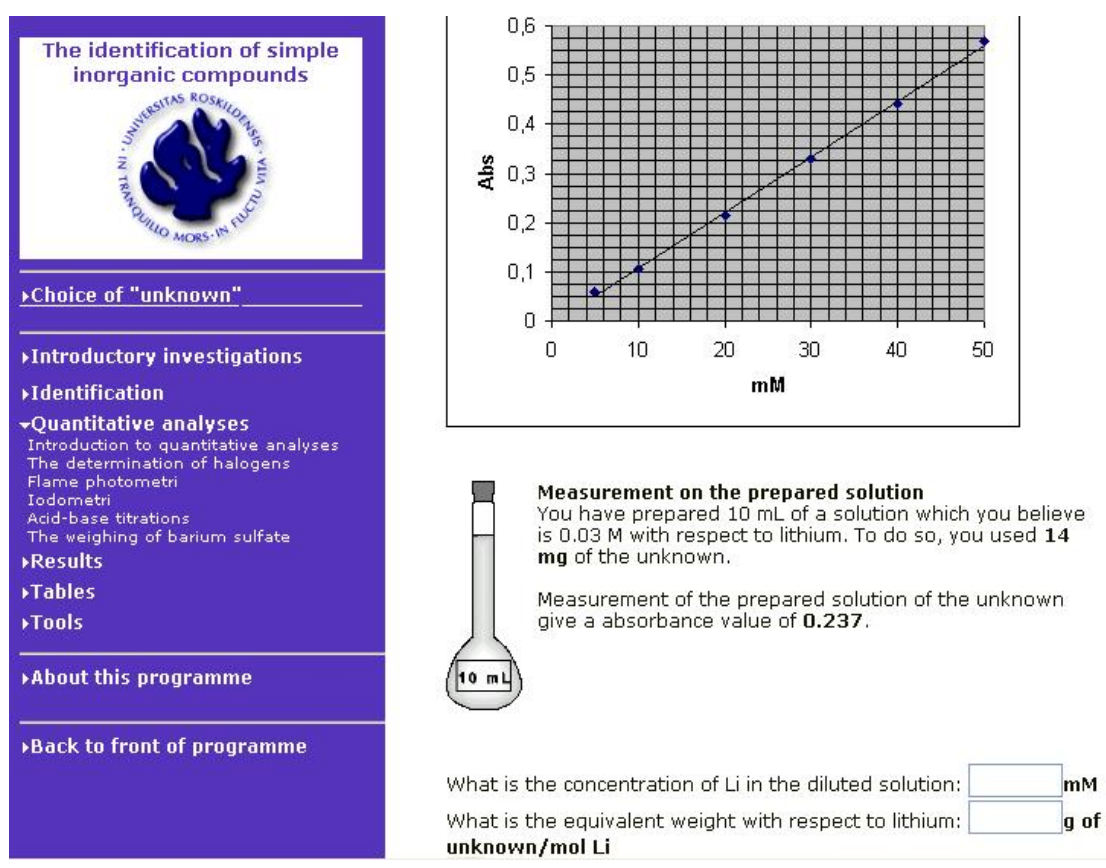

\section{Evaluation of the method}

Three successive groups of students ( $\mathrm{n}=92$ in total) were introduced to the programme as a part of their lab course. All students were working in pairs for an hour, and their interactions (with the program and each other) were observed. After the session they were asked to complete a questionnaire evaluating the session. Two of the groups were additionally assigned for pre and post assessment test. The session was designed with a 15 minutes pre test, the SimuLab-assignment for one hour, and a post test of 15 minutes. The same ten questions were used for pre and post test. All questions in the tests were weighted equally in the assessment which was designed to explore students' understanding of principles and calculation of stoichiometry, and also the use and interpretation of some of the simple tests in the laboratory. While the first group of students were used to adjust the design of the pre- and post-tests, the performance of the second group (32 students) was assessed. The format of the tests was a mix of multiple choice, "write down your answer", and simple calculation questions. For the latter group, the same questions were given in different order in the pre and post test. During the session four pairs of students were recorded on video for further analysis, and six of these students were interviewed using a semi-structured interview approach. Three of the questions are given below as examples (with answers in red): 
To a colourless solution of a pure compound in water is added 1 drop of $0.01 \mathrm{M}$ potassium permanganate. The solution stays colourless.

This experiment suggests, that the solution contains a component, which (tick the right answer(s))

- $\quad$ is able to oxidise potassium permanganate

- $\quad$ is not able to oxidise potassium permanganate

- $\quad$ is able to reduce potassium permanganate $\sqrt{ }$

- $\quad$ is not able to reduce potassium permanganate

Which components of a pure compound will form a gas when heated with diluted hydrochloric acid. The gas is identified by the formation of a white precipitate when lead into a solution of barium hydroxide [write formula(s) and name(s)] $\mathrm{HCO}_{3}{ }^{-}, \mathrm{CO}_{3}{ }^{2-}, \mathrm{HSO}_{3}{ }^{-}, \mathrm{SO}_{3}{ }^{2-}$ (hydrogen-)carbonate, (hydrogen-)sulfite

A pure white, crystalline compound $\mathrm{X}$ is soluble in water. The following equivalent masses are found: $89 \mathrm{~g} \mathrm{X} / \mathrm{mol} \mathrm{Na}$ and $178 \mathrm{~g} \mathrm{X} / \mathrm{mol} \mathrm{P}$. What is the empirical formula of $\mathrm{X}$. $(\operatorname{Help}: \mathrm{M}(\mathrm{Na})=23 ; \mathrm{M}(\mathrm{P})=31$; $\mathrm{M}(\mathrm{H})=1 ; \mathrm{M}(\mathrm{O})=16 \mathrm{~g} / \mathrm{mol}) \mathrm{Na}_{2} \mathrm{HPO}_{4} \cdot 2 \mathrm{H}_{2} \mathrm{O}$

\section{Results and discussion}

Interviews with students after the session with SimuLab and the questionnaires revealed that the students liked to work with this simulation program. They tended to enjoy working with it, they found it motivating, and they realised that it created a lot of experience, which they believed could be remembered more easily. We assume that opportunity to practise the acquired theoretical knowledge in the context of a realistic problem-solving task, free of the procedural challenges, awakened the students' motivation and joy to learn; in contrast a lot of students normally find the memorisation of empirical facts to be dull and difficult.

The interviews demonstrated that students understood the purpose of the program and acknowledged its relation to other parts of the teaching set up; (as one of the students expressed it) (in this and following transcripts, the underlining is ours) :

"In the lab you practise skills - with the simulation you focus on principles".

In other words, the students perceived SimuLab as a theoretical part of chemical experience with classical analysis, while the real laboratory environment as an opportunity to practise procedural skills and get chemical experience. This aspect was also a clear trend in the questionnaires.

This type of feedback from students is the same as one of the main findings in a parallel study by Woodfield et al. (2004) of the use of a Virtual simulation in qualitative inorganic analysis. They also suggest that it is "perhaps the largest educational benefit" that the students can focus on principles, and we agree with that. One lesson to draw is obviously that even very simple laboratory techniques require attention that causes cognitive load. Every laboratory technique has to be understood and learned how to carry out. In open-ended assignments, such as the one provided by the SimuLab, the student further has to decide what techniques should be used and in which order.

The comment of one of the students not only confirms the awareness of his cognitive limitations but also emphasizes the supportive role of the programme in the learning process:

"In the lab, you easily forget the principle of the experiment. You concentrate on following the procedure correctly. Here [with the simulation] this aspect is absent, and you can concentrate on what happens".

As we have emphasized before, by allowing students to perform investigations without practising 'hands-on activities', they are spared from focusing on lower level cognitive skills. Furthermore, students confessed that in the laboratory they often make procedural mistakes, which implies a time consuming repetition to reach the same stage of the procedure. This 
repetition is much faster in the simulation and saves not only time but also frees up students' attention for the higher order processes, such as the interpretation of investigation results:

"You save the time it takes to do an experiment - then you could focus on principles: why does the experiment turn out in this way?” .

Students experienced the simulation as a time saving way to extend their chemical experience with simple salts and the laboratory procedures of this classical analysis scheme.

The simulation apparently inspired students to reflect not only on the learning method but also on the chemical contents:

"It helped me to think in a chemical way".

This means that by reducing the cognitive load SimuLab also has the potential of supporting students' development of meta-cognitive skills. We can therefore assume that consistent with the intentions SimuLab seems to provide help for the student by sharing the cognitive load, and thus scaffolds students reasoning and learning.

A comment from a student on the apparent logic of the programme hides a confirmation that it inspired him to think in a relevant schema:

"[The programme is] very good, because it helps you to think in a logical way".

Much learning in chemistry is based on the recognition of patterns and thinking in schemas. Apparently SimuLab helps students to construct such a schema. This is also a confirmation of one of the main outcomes of the study by Woodfield et al. (2004) who reported students' experience of being able to "think like chemists".

Another aspect is the benefit coming from the students working in pairs. We found that the SimuLab-programme initiates a dialogue among the collaborating peers. It provides a natural setting for explanation during investigation, and thus an opportunity for students to articulate and share their thoughts and knowledge in a problem-solving situation. It was emphasised by students' in responses to questionnaires that they appreciated the dialogue with a fellow student about the assignment. From our observation it was also obvious that their collaboration functioned as a way to work with the understanding of chemical principles. This finding supports the literature on self-explanation as an effective meta-cognitive strategy improving students learning (Chi et al., 1989; Aleven and Kocdinger, 2002). Thus discussions during the session, supported by verbal feedback from the program, create opportunities for a better understanding of chemical concepts, principles and methods.

"We talk about why we do this and that [experiment in the simulation] and then you become more conscious about the reasons - you argue instead of just trying".

Apparently, in the lab, reasoning and arguing about which experimental step to take next may be replaced by trial and error. The feedbacks from the programme and from the fellow student support the verbalisation of the student's conceptions and understanding of procedures and concepts, thus functions as a facilitator of the individual learning processes.

Verbal confrontation during collaboration may also assist students in eliminating some (silly) misunderstandings and help them to clarify their understandings right away. This may be illustrated by the following piece of dialogue on a screen-experiment showing how $\mathrm{pH}$ changed while drops of hydrochloric acid were added to an aqueous solution of the actual sample (which was neutral in the first place).

S1: Our sample is strongly acidic.

S2: No, our solution went acidic as we added $\mathrm{HCl}$.

S1: Oh, yes, of course.

S2: Our solution was neutral.

S2 (Concludes): It is not a buffer. We should think of an anion of a strong acid. 


\section{S1: Right.}

Another type of misunderstanding is the shaky use of terminology for concepts. This may be corrected immediately, if the peer knows. The benefit of such discussions is obvious here (in this test KI-paper is used to demonstrate a redox-property of the sample):

S1: This is the test for reducing power, isn't it?

S2: No, oxidising.

(They observe a brownish colour on the paper.)

S1: Something is happening. Our sample is oxidising, isn't it?

S2: Yes it is.

The SimuLab setting apparently also helps the students to support each other by formulation and checking what they see and may conclude. As the following dialog illustrates students deduce correctly from observation (here considering if alkali metal ions are present or not in the 'unknown') in a discussion, which eventually falsify their own hypothesis/expectation. (A sample in a flame - cf. Figure. 2 - not containing alkali metal ions):

S1: Our flame is blue.

S2: It's blue, yes.

$\mathrm{S} 1:$ It's not Li, then.

S2: No, neither Li or Na.

S1: Agree.

S2: Which color does K give?

S1: Don't remember, but Na is yellow.

S2: $N a$ is orange and Li is red.

(A few seconds' break in conversation, obviously for thinking.)

S1: Normally a flame is bluish, isn't it?

S2: I think so.

S1: This means that we haven't got anything.

S2: Agree, but it would have been nice if we had $\mathrm{K}(\mathrm{hmmm})$ - a flame is blue in itself.

S1 (concludes): Not Li, not Na, not K.

Since the SimuLab is provided on the web, it allows students to access this virtual laboratory for practising theoretical knowledge, and improve their procedural skills at a time and place chosen by themselves. This aspect was also appreciated and emphasized by students, since you can sit at home and practise in the laboratory.

The students didn't consider the programme to be too simple or too difficult, because (as they state) it simulates the actual laboratory procedures and techniques quite closely. They also stated independently (they were not prompted by a question about this aspect), that SimuLab is a valuable supplement to real laboratory work and other parts of the teaching. The reason is that it reduces the cognitive burden in the period where the tests and procedures in the laboratory are not familiar to the students; the absence of overload then makes thinking and understanding possible and thus allows reflection.

The students stressed the fact, that a simulation cannot replace laboratory work. This finding is in line with reports on the use of Computer Aided Assessment (CAA) quizzes (Price, 2006) with formative feedback. In this case CAA quizzes were considered helpful by the students, but were not regarded as a substitute for the contact with tutors. In the present case the authentic aspect seems to play an important role to the students, who acknowledge that real experiments give a far more complete experience of reactions and other properties of compounds and mixtures. Indeed, a certain amount of practising of procedural skills in the lab is necessary for the contextualization of the students' declarative knowledge; in addition they have to become sufficiently confident with the procedures to use the inherent chemical 
principles in any situation. Accordingly, SimuLab can probably not be used as a pre-lab. There are too many techniques and procedures to know or recall for a present day young student, who is not asked to learn a fairly large laboratory manual by heart before he or she is given access to the laboratory. The authentic experience is really important in learning as the students themselves also stressed in their response. On the other hand, SimuLab can certainly act as a post-lab and an 'in-between-lab'. In this case it was used as an 'in-between-lab', which refers to the fact that the SimuLab exercise was not introduced early in the laboratory assignment period, but rather in the middle, by which time the students have had some experience with the procedures and techniques in the lab and were able to link them to underlying chemical principles to a larger extent than in the beginning of the course period. Some students also pointed to the potential use of SimuLab as an optional post lab.

Although the programme was seen as a supplement to the real laboratory, it was also regarded as a kind of extension of the laboratory time. One of the students said: "Through the work [with the simulation] we came across a lot of compounds and their reactions with different solutions". Apparently, to work with the simulation was considered to be a way to get more experience with reagents and reactions. The students felt to have learned more from the laboratory assignment and simulation in combination. The results from the pre and post tests related to a SimuLab session illustrated in Figure 7 confirmed students' own impression of the improvement. Even though the simulation took only one hour, the assessment test proves learning gain.

Comparison of the pre and post test results analysed for one group of 32 students suggests that the majority of students apparently increased their confidence with stoichiometry and principles of laboratory procedures (both of which areas were practised through the programme), and got a better grasp of some relevant chemical concepts.

Figure 7: The result for 32 students of pre and post test containing ten questions, which were assessed with equal weight. Average score in pre test: 3.50; average gain (Delta): 1.54 in one hour.

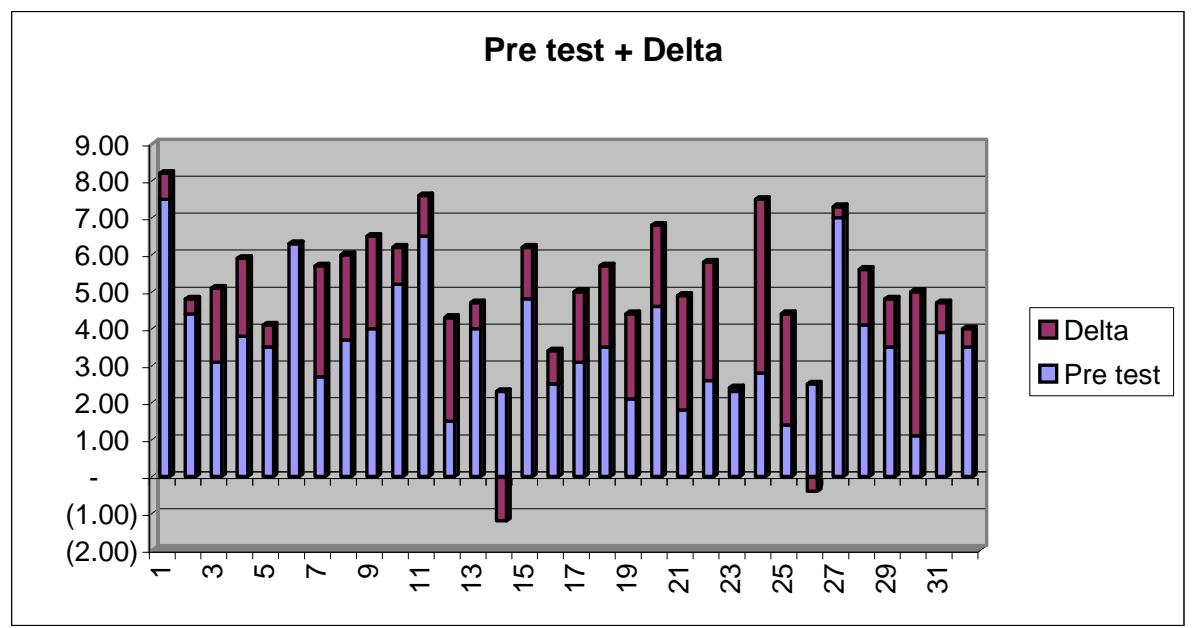

\section{Conclusion}

SimuLab was intended to facilitate students' knowledge construction in a simulated laboratory environment by providing distinctive methods for letting students engage in cognitive activities that are otherwise out of their reach. In the real laboratory it is not always possible for novice learner, to subtract from challenges related to the accomplishment of 
procedures the lower order cognitive skills, which increases the students' cognitive load. By performing tasks demanding lower level skills, SimuLab reduces cognitive load allowing students' attention to be directed towards the higher order processes and leaving more room for scientific reasoning. This investigation of students' reactions and learning gain from the work with the program clearly indicates that the students acknowledge the learning potential of the simulation programme, and their improved learning of the performed task support it. SimuLab seems therefore to provide opportunities for students to promote contextualised scientific reasoning, and facilitate their learning. This result is in agreement with other studies investigating students' learning gain from work with computer-based learning environments that diminish cognitive load (Lajoi, 1993; Lajoi et al.,1998, 2001, White and Frederiksen, 1998, Mayer and Moreno, 2003). A virtual investigation that is thoroughly co-ordinated with practical laboratory assignments and other activities may certainly be a valuable teaching and learning tool that engage students and facilitate their learning processes.

SimuLab, by being a simulation of a laboratory assignment functions as an extension of laboratory time in a cheaper way than the real thing. Working with SimuLab is an asset to the chemical experience obtained in the real laboratory, which is one of the main aims of laboratory work in upper secondary and introductory tertiary education

\section{Notes}

1. An earlier version of this work was presented at the $7^{\text {th }}$ ECRICE, Ljubljana, 2004 (Josephsen and Kristensen, 2004).

2. Readers who have worked through the problem in the Box may like confirmation that compound A is carnallite, $\mathrm{KCl} \cdot \mathrm{MgCl}_{2} \cdot 6 \mathrm{H}_{2} \mathrm{O}$.

\section{Acknowledgements}

This project has received financial support from the former Danish Centre for Educational Development of University Science. Thanks are also due to Keld Nielsen, who did most of the programming.

\section{References}

Aleven V. and Koedinger K., (2002), An effective metacognitive strategy: learning by doing and explaining with a computer-based Cognitive Tutor, Cognitive Science, 26, 147-179.

Baddeley A.D., (1992), Working memory, Science, 255, 556-559.

Bannert M., (2002), Managing cognitive load - recent trends in cognitive load theory, Learning and Instruction, 12, 139-146.

Chi M., Bassok M, Lewis M., Reimann P. and Glaser R., (1989), Self explanation and self regulation strategies-investigating the effects of knowledge acquisition activities on problem solving, Cognitive Science, 5, 145-182.

Garratt C.J., (1997), Virtual investigations: ways to accelerate experience, University Chemistry Education, 1, 19-27.

Johnstone A.H., (1997), “...And some fell on good ground”, University Chemistry Education, 1, 8-13. Johnstone A.H., (1999), The nature of chemistry, Education in Chemistry, 36, 45-47.

Johnstone A.H., Sleet R.J. and Vianna, J.F., (1994), An information processing model of learning: its application to an undergraduate laboratory course in chemistry, Studies in Higher Education, 19, 77-87.

Johnstone A.H., Watt A.J.J, and Zaman T.U., (1998), The students' attitude and cognition change to a physics laboratory, Physics Education, 33, 22-28.

Josephsen J., (2003), Experimental training for chemistry students: does experimental experience from the sciences contribute? Chemistry Education Research and Practice, 4, 205-218. 
Josephsen J., (2005), Online simulation of classical inorganic analysis - interactive, self-instructing simulations give more lab-time, Proceedings from the European Variety in Chemistry Education meeting, Kraków.

Josephsen J. and Kristensen A.K., (2002), Simulation of classical inorganic analysis on-line - what do the students think? Paper presented at the Variety in Chemistry Teaching Meeting, Keele. Oral 6.

Josephsen J. and Kristensen A.K., (2004), Simulation of classical inorganic analysis on-line. How do the students react? Proceedings from the $7^{\text {th }}$ ECRICE, Ljubljana, 158-168.

Lajoie S.P., (1993), Computer environments as cognitive tools for enhancing learning, In: Lajoie, S.P. and Derry, S.J.(eds.), Computers as cognitive tools, (Lawrence Erlbaum Hillsdale, New Jersey, 261-288.

Lajoie S.P., Azevedo R. and Fleiszer D.M., (1998), Cognitive tools for assessment and learning in a high information flow environment, Journal of Educational Computing Research, 18, 205-235.

Lajoie S.P., Lavigne M.C., Guerrera C. and Munsie S.D., (2001), Constructing knowledge in the context of BioWorld, Instructional Science, 29, 155-186.

Langmuir I., (1950), Phenomena, atoms, and molecules, Philosophical Library p. 109 (New York)

Mayer R.E. and Moreno, R., (2003), Nine ways to reduce cognitive load in multimedia learning, Educational Psychologist, 38, 43-52.

Miller G.A., (1956), The magical number seven plus or minus two: some limits on our capacity for processing information, Psychological Review, 63, 81-97.

Price G., (2006), Computer aided assessment and formative feedback - can we enhance students' early experience at University? Wavelength, 2, 10.

Simon H., (1974), How big is a chunk? Science, 183, 482-488.

Shiffrin R.M. and Schneider W., (1977), Controlled and automatic human information processing: II. Perceptual learning, automatic attending, and a general theory, Psychological Review, 84, 127190.

Sweller J., (1988), Cognitive load during problem solving: effects on learning, Cognitive Science, 12, 257-285.

Sweller J. and Chandler P., (1991), Cognitive load theory and the format of instruction, Cognition and Instruction, 8, 292-332.

van Bruggen J.M., Kirschner P.A.A. and Jochems W., (2002), External representation of argumentation in CSCL and the management of cognitive load, Learning and Instruction, 12, 121-138.

White B.Y. and Frederiksen J.R., (1998), Inquiry, modeling, and metacognition: making science accessible to all students, Cognition and Instruction, 16, 3-18.

Woodfield B.F., Catlin H.R., Waddoups G.L., Moore M.S., Swan R., Allen A. and Bodily G., (2004), The Virtual ChemLab project: a realistic and sophisticated simulation of inorganic qualitative analysis, Journal of Chemical Education, 81, 1672-1678. 